\title{
Aninha, Gertrudes e suas dores: a condição feminina na escrita de Augusta Faro
}

Denise Lima Gomes da Silva"

\section{Resumo}

Neste artigo, buscamos refletir sobre a representação da identidade feminina nos contos "A ceia de Aninha" (2001) e "Gertrudes e seu homem" (2004), ambos da escritora Augusta Faro. Tomamos como aporte teórico o diálogo entre os estudos culturais, as teorias de gênero e a literatura. A interação entre esses campos permite refletir como o texto literário resgata e problematiza aspectos que atravessam as práticas culturais. Sendo a identidade uma construção cultural discursiva fluida, procuramos olhar de que forma os contos em questão (re) produzem universos que legitimam as formas de pensar o masculino e o feminino. Buscamos analisar a maneira como Aninha e Gertrudes, as protagonistas dos contos, lidam com os papéis de gênero e procuram solucionar o caráter conflituoso da sua condição existencial.

Palavras-chave: Cultura. Gênero. Identidade.

\section{Introdução}

Este trabalho tem como proposta analisar de que forma a identidade feminina é representada nos contos "A ceia de Aninha" (2001) e "Gertrudes e seu homem" (2004), ambos da escritora brasileira Augusta Faro. Procuramos refletir sobre a construção das personagens femininas e sua relação com a estrutura ideológica dominante, no caso, a patriarcal. A análise procura observar de que forma as duas personagens transitam pelos papéis de gênero e procuram solucionar o caráter conflituoso da sua condição existencial. Tomamos com aporte teórico o diálogo entre os estudos culturais, as teorias de gênero e a literatura.

\footnotetext{
Pós-doutorado em andamento financiado pela Coordenação de Aperfeiçoamento de Pessoal de Nível Superior no Programa de Pós-Graduação em Ciências da Linguagem, da Universidade Católica de Pernambuco. E-mail: dslima@gmail.com
} Data de submissão: mar. 2017 - Data de aceite: mar. 2018
http://dx.doi.org/10.5335/rdes.v14i1.6801 
Em Candido (2000) e Moser (1998), podemos perceber o diálogo estabelecido entre a literatura e os estudos culturais enquanto horizonte frutífero na abordagem da produção literária. A interação entre os campos aponta caminhos para a compreensão da maneira pela qual o texto literário resgata e problematiza aspectos que atravessam as práticas culturais. Dentro do vasto universo que abarca os estudos culturais, deteremo-nos, neste trabalho, na questão da identidade abordada por Stuart Hall (2006, 2011, 1997) e Zygmunt Bauman (2005). Ambos os teóricos apresentam o caráter fluido da identidade na pós-modernidade e refletem sobre a crise instaurada na noção de sujeito do iluminismo, baseada na concepção cartesiana de um indivíduo centrado e unificado. Esse conceito será abordado também nas teorias de gênero propostas por Joan Scott (1990, 1992, 1999), Linda Nicholson (2000), Donna Haraway (2000), Teresa Lauretis (1994) e Judith Butler (2013, 2014).

É importante destacar a contribuição das teorias feministas no que se refere ao conceito de gênero como aporte de análise. Essas teorias nos permitem observar de que forma as construções historicamente marcadas (re)produzem universos culturais que legitimam as formas de pensar o masculino e o feminino. Embora Pierre Bourdieu (1996, 1998, 2002) não elabore uma teoria de gênero, sua proposta é importante para este trabalho, uma vez que aponta maneiras de apreender a lógica simbólica da dominação.
Portanto, este artigo está divido em três seções; na primeira, trataremos da questão da identidade e o seu caráter fluido; em seguida, abordaremos as noções de gênero; por fim, faremos a análise dos contos em questão.

\section{Identidade e seu caráter fluido}

Uma das discussões centrais sobre a questão da identidade encontra-se, como coloca Woodward (2011), na tensão entre as perspectivas essencialistas e não essencialistas. Se, de um lado, a definição essencialista da identidade contempla a ideia de que existe um conjunto cristalino, autêntico de características, inserido em um contexto partilhado que não se altera ao longo do tempo; de outro, a perspectiva não essencialista busca olhar as formas pelas quais as definições mudam ao longo de um percurso.

Woodward (2011) defende que existem questões mais profundas que ultrapassam a fronteira desse binarismo. É preciso levar em consideração que a identidade está vinculada a processos históricos que envolvem aspectos sociais, políticos e econômicos, e cada um deles a constrói e reconstrói de diferentes maneiras. Nesse âmbito, a autora defende ser pertinente observar a maneira como as pessoas assumem suas posições de identidade e se identificam com elas e ainda por que as pessoas investem nas posições que os discursos da identidade oferecem. 
A cultura molda a identidade ao dar sentido à experiência e ao tornar possível optar, entre as várias identidades possíveis, por um modo específico de subjetividade (WOODWARD, 2011, p. 19).

De acordo com Bauman (2005), a questão da identidade surge porque existe mais de uma ideia para evocar e manter unida a comunidade, porque existem tantas ideias e princípios em torno dos quais se desenvolve uma comunidade de indivíduos que é preciso comparar, fazer escolhas, fazê-las repetidamente, reconsiderar escolhas feitas anteriormente, tentar conciliar demandas contraditórias e frequentemente incompatíveis.

Os discursos e consequentemente os sistemas de representação constroem lugares em direção aos quais os sujeitos respondem, como observa Woodward (2011). Sem esquecer que toda prática de significação envolve relações de poder, inclusive poder para definir quem é "incluído" ou "excluído" em um determinado constructo, a autora dialoga com Hall (1997), quando coloca que é preciso examinar a forma como a identidade se insere no circuito da cultura, assim como a forma como a identidade e a diferença se relacionam com a discussão sobre a representação.

De acordo com Hall (1997), para que possamos examinar os sistemas de representação, é necessário analisar a relação entre a cultura e o significado. Os sistemas de representação envolvem as práticas de significação e os sistemas simbólicos, ao mesmo tempo em que produzem significados, produzem também identidades, nas quais os sujeitos são posicionados por meio de representações.

Para Hall, o termo identidade significa:

[...] o ponto de encontro, o ponto de sutura, entre, por um lado, os discursos e as práticas que tentam nos "interpelar", nos falar ou nos convocar para que assumamos nossos lugares como os sujeitos sociais de discursos particulares, e, por outro lado, os processos que produzem subjetividades, que nos constroem como sujeitos aos quais se pode "falar" (HALL, 2011, p. 111-112).

De acordo com Silva (2011), identidade e diferença são inseparáveis. Em um primeiro momento, a identidade parece conter em si uma certa positividade, pode ser definida como simplesmente aquilo que sou: sou mulher, sou negra, sou nordestina. Entretanto, como assevera Silva (2011), a firmação "eu sou", como, por exemplo, "eu sou nordestina", expressa uma cadeia extensa de expressões negativas de identidade, de diferenças, dizer "eu sou nordestina" significa dizer "eu não sou paulista", "eu não sou gaúcha”. Sendo assim, as afirmações sobre identidade só fazem sentido em sua relação com as afirmações de diferença.

De acordo com Silva (2011), identidade e diferença partilham uma importante característica: resultam de criações linguísticas, o que significa dizer que são criadas por meio de atos de linguagem. Sobre essas considerações, Silva (2011) recorre ao pensamento pós-estruturalista de Derrida. Em Derrida (1976), o caráter indeterminado da linguagem é pensado em virtude do conceito de signo. O signo é um sinal, um traço que está 
no lugar de outra coisa. O signo não é o referente, mas está em lugar de. O signo seria a promessa da presença e, pela sua incompletude, carregaria em si o traço daquilo que substitui, como também o traço daquilo que não é, isto é, a diferença. Sendo assim, seguindo a perspectiva colocada pelo autor, a linguagem se apresenta enquanto estrutura instável.

Ao relacionar as noções de diferença e de identidade enquanto atos de linguagem a partir do pensamento de Derrida, Silva levanta uma questão importante:

[...] na medida em que são definidas, em parte, por meio da linguagem, a identidade e a diferença não podem deixar de ser marcadas, também, pela indeterminação e pela instabilidade (SILVA, 2011, p. 80).

Silva (2011) chama atenção para o fato de que a identidade e a diferença são instáveis e indeterminadas tanto quanto a linguagem da qual dependem, uma vez que a linguagem enquanto sistema de significação é uma estrutura instável.

\section{Como afirma Hall:}

[...] é precisamente porque as identidades são construídas dentro e não fora do discurso que nós precisamos compreendê-las como produzidas em locais históricos e institucionais específicos, no interior de formações e práticas discursivas específicas, por estratégias e iniciativas específicas. Além disso, elas emergem no interior do jogo de modalidades específicas de poder e são, assim, mais o produto da marcação de diferença e da exclusão do que o signo de uma unidade idêntica, naturalmente constituída, de uma "identidade" em seu significado tradicional - isto é, uma mesmidade que tudo inclui, uma identidade sem costuras inteiriças, sem diferenciação interna (HALL, 2011, p. 109).
Para Hall (2006), o homem, inserido num contexto fragmentário, vive sob o signo da pós-modernidade. Descentrado das concepções iluministas, o homem pós-moderno vive um novo estágio de sua identificação, incluído na diversidade de culturas do mundo globalizado, em que as identidades vão sendo constantemente construídas e reconstruídas. As transformações associadas à modernidade libertaram o indivíduo de seus apoios estáveis nas tradições e estruturas. Os descentramentos do sujeito, de acordo com o autor, ocorrem devido a uma série de rupturas nas áreas do conhecimento. Hall (2006) aponta cinco grandes avanços na teoria social e nas ciências humanas, na segunda metade do século $\mathrm{XX}$, que contribuíram para esses deslocamentos do sujeito moderno.

$O$ primeiro descentramento surge com a reinterpretação, na década de 1960, dos trabalhos de Karl Marx. De acordo com Hall (2006), ao afirmar que os homens fazem a história sob as condições que lhes são dadas, Marx teria deslocado duas proposições-chave da filosofia moderna: a primeira é a concepção de que há uma essência universal de homem, e a segunda, de que essa essência é o atributo de cada indivíduo singular, o qual é seu sujeito real.

O segundo descentramento veio com a teoria do inconsciente de Freud. Com essa teoria, o sujeito cognoscente e racional constituído por uma identidade fixa e unificada foi substituído por um sujeito cujas identidade, sexualidade e 
estrutura de desejos eram formadas com base em processos psíquicos e simbólicos do inconsciente e funcionariam de acordo com uma lógica diferente daquela da razão do sujeito de Descartes. Aidentidade, afirma Hall,

[...] surge não tanto da plenitude da identidade que já está dentro de nós como indivíduos, mas de uma falta de inteireza que é preenchida a partir de nosso exterior, pelas formas através das quais nós imaginamos ser visto por outros (HALL, 2006, p. 39).

O terceiro descentramento surge com base nos estudos linguísticos de Ferdinand de Saussure. De acordo com Hall (2006), Saussure considera que a língua é um sistema social, não um sistema individual, e preexiste a nós. Os significados surgem nas relações de similaridade e diferença que as palavras têm com outras palavras no interior da língua, não sendo, portanto, fixos, transportando com elas o eco de outros significados.

O estudo do filósofo e historiador Michel Foucault e sua genealogia do sujeito moderno caracterizam o quarto descentramento. Segundo Hall (2006), Foucault destaca o que ele chama de poder disciplinar. $\mathrm{O}$ poder disciplinar, representado por instituições, como quartéis, escolas, prisões, hospitais e clínicas, está preocupado, em primeiro lugar, com a regulação, a vigilância, o governo da espécie humana ou de populações inteiras, e, em segundo lugar, com o indivíduo e com o corpo.

O quinto descentramento é marcado pelo impacto do feminismo. Movimento considerado tanto pelo seu valor crítico e teórico quanto pelo seu valor social, o feminismo levantou questionamentos importantes, como, por exemplo: a distinção entre privado e público; a forma como somos formados e produzidos como sujeitos generificados, politizando a subjetividade, a identidade e o processo de identificação (homens/mulheres, mães/ pais, filhos/filhas); a noção de homens e mulheres como parte da mesma identidade, a humanidade substituindo-a pela questão da diferença sexual; entre outras contribuições.

Com a descrição dos cinco descentramentos, Hall (2006) procura mostrar como o sujeito do iluminismo, caracterizado por uma identidade fixa e estável, foi descentrado, resultando nas identidades abertas, contraditórias, inacabadas, fragmentadas do sujeito pós-moderno. $\mathrm{Na}$ modernidade tardia, as identidades não são unificadas, nem singulares, elas estão cada vez mais fragmentadas e fraturadas, multiplamente construídas em discursos, práticas e posições, constantemente em processo de mudança e transformação.

Apontando também a arena fluida sobre a qual a identidade se move, Bauman (2005) destaca que a identidade assim como o sentimento de pertença não têm a solidez de uma rocha, nem garantia para toda uma vida, pelo contrário, são bastante revogáveis e negociáveis. A maneira como agem os indivíduos, os caminhos que percorrem, as decisões que tomam são fatores cruciais tanto para 0 
pertencimento quanto para a identidade. Em outras palavras,

[...] a idéia de "ter uma identidade" não vai ocorrer às pessoas enquanto o "pertencimento" continuar sendo o seu destino, uma condição sem alternativa. Só começarão a ter essa idéia na forma de uma tarefa a ser realizada, e realizada vezes e vezes sem conta, e não de uma só tacada (BAUMAN, 2005, p. 18).

$\mathrm{O}$ autor enfatiza que as identidades flutuam no ar, algumas são de nossa própria escolha, outras não, são infladas e lançadas a nossa volta pelas pessoas.

É justamente enquanto prática discursiva fluida que olhamos a questão da identidade feminina, que, por sua vez, tem sido amplamente discutida nas teorias sobre gênero pelas pesquisas realizadas por Scott (1990), Nicholson (2000), Haraway (2000), Lauretis (1994), Butler (2013) e pela reflexão de Bourdieu (1996, 2002).

\section{Questões de gênero}

É notório que a trajetória das mulheres tem sido marcada, ao longo da história, por processos descontínuos, emergentes de transformações sociais, econômicas e políticas, vividos no seio da sociedade. Como bem coloca Rosa Montero (2007), com o surgimento do positivismo e a morte dos deuses, a sociedade começou a questionar a ordem natural e o porquê das coisas. Há séculos tenta-se compreender os inúmeros porquês relacionados à condição da mulher. Por que as sociedades diferenciam a tal ponto homem e mulher? Como se estabeleceram as hierarquias? Quando isso aconteceu? Sempre foi assim? Montero (2007) afirma que ainda não há respostas claras a essas perguntas, e as teorias sobre uma primeira fase do matriarcado na humanidade não são suficientemente demonstradas.

Alguns acontecimentos históricos contribuíram para despertar a sociedade acerca da questão da mulher. Na Europa, no século XVIII, com os ideais de justiça e fraternidade, emergentes com a Revolução Francesa, homens e mulheres começaram a perceber que a igualdade ou era para todos os indivíduos, ou não era para ninguém. Apareceram clubes e associações de mulheres e existiram revolucionárias feministas, a exemplo de Olympe de Gouges e Théroigne de Méricourt (MONTERO, 2007). Na tradição anglo-americana, temos Mary Wollstonecraft como a primeira teórica feminista. Em seu trabalho A vindication of the rights of woman, publicado em 1792, Wollstonecraft elaborou uma teoria social da subordinação das mulheres e articulou um ativismo político que se conservou no centro do feminismo ocidental (1792 apud EDGAR; SEDGWICK, 2003).

Em meados do século XIX, com a Revolução Industrial, o modo de vida familiar tradicional começa a sofrer transformações. A condição da mulher foi encarada pela primeira vez como um problema social. Além disso, a sociedade vivia $o$ auge das correntes positivistas e 
do cientificismo (MONTERO, 2007). É importante observar que inicialmente o movimento feminista preocupava-se com as igualdades política e econômica das mulheres diante dos homens. Somente após a Segunda Guerra Mundial, o feminismo toma novos rumos, as feministas procuram alcançar a compreensão da natureza cultural da opressão, observando as formas como as próprias instituições culturais alicerçam e perpetuam a subordinação das mulheres (EDGAR; SEDGWICK, 2003).

De acordo com Joan Scott (1992), a história das mulheres surge como campo definível principalmente a partir da década de 60 do século XX. Os estudos feministas nascem influenciados pelo movimento dos direitos civis. Entretanto, é importante lembrar que as décadas de 1920 e 1940 foram marcadas por importantes discussões sobre a questão da mulher, a exemplo dos escritos de Virginia Woolf e de Simone de Beauvoir. A filósofa francesa, em seu livro $O$ segundo sexo (2009), afirma que não se nasce mulher, torna-se mulher. Em sua frase mais citada, a autora chama atenção para as condições sociais e culturais enquanto responsáveis pela construção das identidades feminina e masculina. A posição de Beauvoir é considerada um avanço para os estudos feministas e para a questão de gênero.

No imenso universo sobre a questão da mulher, Scott (1990) observa três posições teóricas que as feministas empregam nas abordagens de análise do gênero: a teoria do patriarcado, a teoria marxista e a teoria psicanalítica. De maneira geral, a teoria do patriarcado questiona a desigualdade entre homens e mulheres e localiza a opressão na manipulação masculina da sexualidade feminina; a teoria marxista acredita que a opressão é fruto das estruturas sociais e econômicas da sociedade; e a teoria psicanalítica defende que a subjetividade feminina se constrói em uma cultura sexista.

De acordo com Scott (1990), as preocupações teóricas relacionadas à questão de gênero enquanto categoria de análise, enquanto meio de falar sobre os sistemas de relações sociais e entre os sexos, apenas emergiram no final do século XX. Nesse contexto, o termo gênero representa uma tentativa das feministas contemporâneas para reivindicar um terreno próprio de definição, é uma tentativa de insistir sobre a inadequação das teorias existentes que se propõem a explicar a desigualdade entre homens e mulheres.

Scott defende que o feminismo necessita de

[...] teorias que possam analisar o funcionamento do patriarcado em todas as manifestações - ideológicas, institucionais, organizativas, subjetivas, explicando não somente a continuidade, mas também as mudanças no tempo (1999, p. 203).

Para a autora, é preciso analisar as construções de significado e as relações de poder, questionando as categorias unitárias e universais que naturalizam noções, a exemplo da definição de homem e mulher. Seguindo uma perspectiva pós- 
-estruturalista, Scott (1990) propõe um conceito de gênero fundado na História, tendo como núcleo duas proposições ligadas entre si: a primeira é que o gênero é um elemento constitutivo de relações sociais alicerçadas sobre as diferenças percebidas entre os sexos, e a segunda é que o gênero é um modo de dar significado às relações de poder.

A primeira proposição, a noção de gênero enquanto constitutiva de relações sociais baseadas nas diferenças entre os sexos, implica quatro elementos. $\mathrm{O}$ primeiro elemento refere-se ao gênero enquanto símbolo culturalmente construído que evoca representações. $\mathrm{O}$ segundo elemento diz respeito aos conceitos normativos expressos pelas doutrinas religiosas, educativas, científicas, jurídicas e políticas que constroem o sentido de masculino e feminino, fundamentado na oposição binária. $O$ terceiro elemento está relacionado à necessidade de incluir na análise do gênero uma noção de política como uma referência às instituições e à organização social, uma vez que o uso da categoria de gênero não deve ser reduzido ao sistema de parentesco, mas a uma visão mais ampla, que abarque $o$ mercado de trabalho, a educação, o sistema político. O quarto aspecto do gênero é a identidade subjetiva, que critica a concepção universal da psicanálise em que as identidades de gênero são fundadas unicamente no medo da castração, negando que as identidades são construídas e relacionadas às representações sociais historicamente situadas.
Sobre a segunda proposição, a noção de gênero enquanto modo de dar significado às relações de poder, a autora afirma que o gênero é um campo pelo qual o poder é articulado e constituído e tem sido um meio de significação de poder nas tradições judaico-cristãs e islâmicas. Em sua definição, portanto, a autora critica o binarismo e o essencialismo e prioriza a pluralidade e a diversidade, pensando o gênero como um meio de produção de sentidos e de compreensão das diversas formas de interação humana.

Para Nicholson (2000, p. 9), o termo gênero é utilizado de duas formas diferentes, sendo até certo ponto contraditórias. De um lado, é usado em oposição a sexo, para diferenciar o que é biologicamente dado do que é socialmente construído, sendo pensado enquanto personalidade e comportamento, não enquanto corpo; assim, gênero e sexo estão distintos. Por outro lado, a noção de gênero tem sido usada para se referir a qualquer construção social que distingue corpo feminino e corpo masculino. Gênero, então, é pensado não apenas enquanto comportamento e personalidade, mas também enquanto maneiras pelas quais o corpo aparece. Neste contexto, sexo está ligado a gênero. De acordo com a autora, embora o segundo sentido de gênero predomine no discurso feminista, a herança do primeiro sobrevive. "O sexo permanece na teoria feminista como aquilo que fica de fora da cultura e da história, sempre a enquadrar a 
diferença entre masculino e feminino" (NICHOLSON, 2000, p. 10).

De acordo com Lauretis (1994), nos escritos feministas e nas práticas culturais dos anos 1960 e 1970, o conceito de gênero enquanto diferença sexual se encontrava no centro da crítica da representação, do questionamento de teorias de subjetividade e textualidade, de leitura e escrita culturais. A noção de gênero enquanto diferença sexual sustentou as intervenções feministas na arena do conhecimento formal e abstrato, nas epistemologias das ciências sociais e humanas, elaborando práticas e discursos específicos e espaços sociais, como grupo de mulheres, estudo sobre a mulher, nos quais a própria diferença sexual e os conceitos derivados dela pudessem ser afirmados, analisados, especificados ou verificados.

De acordo com Lauretis (1994), o conceito de gênero enquanto diferença sexual impôs duas limitações ao pensamento feminista. A primeira limitação é que o pensamento crítico feminista ficou restrito ao arcabouço conceitual de uma oposição universal do sexo, isto é, a mulher como diferença do homem e ambos universais; ou a mulher como diferença pura e simples, como diferenças das mulheres. A segunda limitação é que esta noção reacomodou o pensamento feminista sem romper os limites da casa patriarcal.

Lauretis (1994) defende, então, a necessidade de um conceito de gênero que não seja preso à diferença sexual e sugere pensar o gênero a partir de um diálogo com Foucault, que vê a sexualidade como uma tecnologia sexual. Diz a autora:

[...] propor-se-ia que também o gênero, como representação e como auto-representação, é produto de diferentes tecnologias sociais, como o cinema, por exemplo, e de discursos, epistemologias e práticas críticas institucionalizadas, bem como das práticas cotidianas (LAURETIS, 1994, p. 208).

Dessa forma, assim como a sexualidade, o gênero não existe a priori nos seres humanos, nem é uma propriedade de corpos, mas

[...] o conjunto de efeitos produzidos em corpos, comportamentos e relações sociais, por meio do desdobramento de uma complexa tecnologia política (LAURETIS, 1994, p. 208).

Ao refletir sobre a modernidade, a universalização dos sujeitos e o movimento feminista, Haraway questiona:

[...] e quem é esse "nós" [mulher] que é enunciado em minha própria retórica? Quais são as identidades que fundamentam esse mito político tão potente chamado nós e o que pode motivar o nosso envolvimento nessa comunidade? (2000, p. 52).

De acordo com a autora, depois do reconhecimento, conquistado de maneira árdua, de que gênero, classe e raça são social e historicamente construídos, não cabe mais pensar esses elementos na base da crença em uma unidade essencial. "Não existe nada no fato de ser 'mulher' que naturalmente una as mulheres. Não existe nem mesmo uma tal situação - 'ser' mulher" (HARAWAY, 2000, p. 52). Esse "ser mulher" trata-se de uma categoria altamente complexa, 
construída por meio de discursos científicos sexuais e de outras práticas sociais questionáveis, afirma a autora.

De acordo com Haraway (2000), na mudança de uma sociedade industrial para um sistema polimorfo informacional, os dualismos orgânicos e hierárquicos que ordenaram o discurso no "Ocidente", desde Aristóteles, e as dicotomias aí envolvidas entre mente e corpo, animal e humano, organismo e máquina, público e privado, natureza e cultura, homens e mulheres, primitivo e civilizado estariam todas ideologicamente em questão.

Mas como questionar esse sistema epistemológico/ontológico? Qual a melhor maneira de problematizar as categorias de significação que sustentam a hierarquia dos gêneros? Essas são algumas questões colocadas por Butler (2013). A autora defende que não existe uma estrutura originária que as identidades imitem, este deslocamento constitui uma fluidez de identidades que sugere uma abertura à ressignificação e à recontextualização.

Gênero, para Butler (2014), não é precisamente o que alguém "é", nem o que alguém "tem", mas o aparato pelo qual a produção do masculino e do feminino se manifesta juntamente com as formas intersticiais, físicas, cromossômicas, hormonais e performativas que o gênero assume. Sendo assim, gênero é o mecanismo pelo qual as noções de masculino e feminino são produzidas e naturalizadas, mas também pode ser o aparato por meio do qual masculino e feminino podem ser desconstruídos e desnaturalizados.
De acordo com Bourdieu (1998), homens e mulheres constroem o mundo social, mas fazem-no a partir de normas e categorias que são construídas pelo mundo. Gênero, raça, classe e outras distinções sociais são construídas socialmente. Bourdieu (2002) defende que a força da ordem masculina se evidencia no fato de que dispensa justificação, a visão androcêntrica se impõe como neutra e não tem a necessidade de se enunciar em discursos que visem a legitimá-la. A divisão entre os sexos parece estar na ordem das coisas para falar do que é normal ou natural. Perpassa as estruturas cognitivas e sociais, funcionando como sistemas de percepção, de pensamento e de ação. O mundo social constrói o corpo como realidade sexuada e como depositário de princípios de visão, como coloca Bourdieu (2002). Entretanto, por maior que seja a concordância entre as divisões objetivas do mundo social e os princípios subjetivos, existe sempre lugar para lutas cognitivas sobre o significado do mundo e, em particular, sobre as realidades sexuais, defende $o$ autor.

\section{Aninha e Gertrudes e suas dores}

O conto "Gertrudes e seu homem", publicado em 2004 na coletânea $25 \mathrm{mu}$ lheres que estão fazendo a nova literatura brasileira, narra a história da protagonista Gertrudes. Gertrudes é dona de um ateliê de costura e casada com Romão, um viajante. A trajetória da personagem se passa 
em uma cidade pequena. $\mathrm{O}$ conto "A ceia de Aninha”, publicado em 2001 no livro A friagem, é narrado em apenas um dia da vida da protagonista, o dia da ceia de Natal, entre os preparativos para a festa, a ceia e a saída dos convidados. Aninha tem um casal de filhos e, em virtude do casamento com Mário, deixou a pequena cidade onde nasceu para viver na cidade grande.

Logo no início da narrativa de "Gertrudes e seu homem", o sofrimento é associado à figura da protagonista. O narrador revela que antes de tudo Gertrudes é uma mulher amarga e imensamente solitária, sugerindo a profunda angústia em que se encontra a protagonista, ao afirmar que:

[...] as amarguras de Gertrudes doíam na alma tropeçante de quem parasse um pouquinho só para observá-las. Havia um sorriso de penumbra sempre lhe embaçando o olhar cor de chuva, de tormento, de desvairo e de profunda solidão (FARO, 2004, p. 127).

Em condição semelhante, encontra-se Aninha. Entretanto, diferentemente de Gertrudes, Aninha não deixa transparecer a dor, é a beleza a sua grande aliada. "Sabia e ressabia: era bonita, às vezes até demais. Esses profundos olhos azuis, pele de pêssego, perfil de camafeu. Trunfos de grande valia" (FARO, 2001, p. 29). Aninha é uma mulher dedicada à casa e aos dois filhos. "A ceia terá toalha de renda [...]. Terá também enfeites novos, coloridíssimos, como convém ser as noites natalinas" (FARO, 2001, p. 29)

Gertrudes é uma mulher de "maturidade acalmada" que chegou só em uma cidadezinha, sem origem, de repente e sem explicação, monta um atelier de costura e rapidamente conquista a freguesia. Gertrudes é uma mulher falante, que "contava grandeza do amor de seu homem", que "tocava a pianola", que "dava corda nos relógios", que "plantava lírios amarelos nos fundos da casa e girassóis no jardim", que "fazia bolos e broa, peta e biscoitos, rocamboles com frutas cristalizadas", que tinha sempre a "toalha rendada de branco céu e, em tudo por tudo, uma zelosa harmonia parecia dançar valsa naquele ambiente". O interior da casa de Gertrudes era sempre "sóbrio, elegante e distinto, bonito de se contemplar", e "a sociedade amou rapidamente aquela mulher" (FARO, 2004, p. 127-128).

Em suas ações, Gertrudes e Aninha procuram recriar um ambiente doméstico de perfeita harmonia. $\mathrm{O}$ perfil feminino das personagens é construído no espaço privado, na vida familiar, e reflete o crivo das imposições sociais que estruturam as relações de gênero. Gertrudes tem um exímio talento para plantar, cozinhar, rendar, bordar e arrumar. No caso de Aninha, o casamento veio para aprimorar sua vocação de brilho.

De acordo com Bourdieu (1996), a família em sua definição legítima é um privilégio social instituído como norma universal, e isso implica simbolicamente ser como se deve ser, dentro da normalidade. No sistema patriarcal, a normalidade representada pela família se apresenta como um lugar naturalmente instituído. É justamente de um lugar naturalizado que Gertrudes e Aninha fa- 
lam. As protagonistas não questionam a sua condição de existência fora do âmbito privado, encontram-se aprisionadas por um ideal de vida internalizado em nome dessa normalidade. $O$ conflito é marcado pela angústia de uma adequação ao estereótipo de gênero, reproduzido pela ideologia patriarcal, alicerçada sobre papéis institucionais. Gertrudes e Aninha criam uma "realidade" sobre si mesmas e sobre suas vidas em busca de pertencimento.

A solução encontrada por Gertrudes é construir um marido imaginário, Romão. $\mathrm{E}$ é em nome de Romão, cujo lugar social é assegurado, que Gertrudes conquista um espaço na cidade em que vive. Ela é conhecida pelas estórias que conta sobre o marido. O cônjuge representa aquilo que outorga o lugar da protagonista na esfera pública, "a aura do marido de Gertrudes crescia com fama audível, indomável” (FARO, 2004, p. 129). Romão representa, como define o narrador, um distinto cavalheiro. Em vários trechos, aparece como um homem sensível, apaixonado, corajoso e dedicado.

[...] Meu marido chegou de viagem tarde da noite, agora dorme [...]. Ama o lar, mas a profissão o consome [...]. Sempre um presente acompanhava o retorno daquele rapaz escalavrado de vítrea aura impermeável e que sufocava $o$ ambiente com um perfume de macho saudável, vigoroso [...] potro de legítima gentileza e incansável ternura [...]. Ele é lindo, altão, moreno claro, tem uns olhos tão verdes como uma folha de parreira nova. É perfumado o homem [...]. Ele tem as mãos longas macias [...]. Esse homem veio do começo do mundo, gente!!! (FARO, 2004, p. 128-129).

Gertrudes ocupa na narrativa um lugar de sujeição, a desigualdade de gênero aparece nos papéis sociais em que ambos ocupam. Romão era viajante e não tinha porto, Gertrudes era costureira e tinha um atelier em casa, fatos que delimitam o lugar do homem na esfera pública e da mulher na esfera privada. Além disso, a protagonista silencia sobre si mesma, sobre sua vida, sobre sua existência, não reclama um lugar próprio no mundo, sua existência é centrada na figura do marido.

Todo mundo que frequentava o ateliê de costura, sempre ouvia as estórias de Romão, esse nome sempre envolto em onírico mistério, ruídos, palpável e, sobretudo, impenetrável (FARO, 2004, p. 128).

Como destaca Bourdieu (2002), a divisão entre os sexos parece estar vinculada àquilo que é considerado a ordem das coisas para falar do que é normal, atravessando as estruturas cognitivas $\mathrm{e}$ sociais, incorporado nos corpos e nos $h a$ bitus dos agentes. E esta divisão sexual funciona como sistemas de percepção, de pensamento e de ação. $\mathrm{Na}$ fala de Gertrudes, a visão patriarcal se legitima com tanta naturalidade que mina na personagem qualquer possibilidade de deslocamento. Gertrudes conduz Romão à perfeição, a ponto de o marido se tornar objeto de desejo das moças da cidade, que resolvem invadir a casa da Gertrudes e finalmente conhecer Romão.

Ao invadir a casa de Gertrudes, as moças se deparam com aquele homem "coberto de linho puro", "dormindo tão justo", "repousado na beleza de um deus grego", "era o dia do fim do mundo, ele ali verdadeiro e completo" (FARO, 2004, p. 131). Podemos observar que os termos "puro", 
"justo", "verdadeiro" e "completo" corroboram para a representação romântica da personagem. Isso pode ser observado no momento da descoberta da inexistência de Romão, que provoca a fúria das moças durante três dias; no ato de amor e ódio, elas estraçalharam o boneco Romão, e cada uma leva para casa um pedaço. Esse pedaço é metaforicamente o pedaço "daquele sonho deitado acima de todas as compreensões" (FARO, 2004, p. 132).

Diferentemente de Gertrudes, o marido de Aninha existe, mas está ausente, e essa ausência é o tormento da protagonista. O narrador não deixa claro o motivo pelo qual Mário está ausente e, em alguns momentos, sugere uma separação. No preparativo para a ceia, a protagonista revive, a cada gesto, as lembranças do seu casamento e a nostalgia da ausência de Mário. Antes de os convidados chegarem, Aninha checa minuciosamente todos os detalhes da ceia e fala ao telefone com seus pais. Nesse momento, a protagonista é tomada pelo profundo sentimento de que algo foi perdido e carregado pelo vento forte, mas logo volta a si, e a preocupação com os convidados é retomada.

$\mathrm{E}$ a eletricidade da árvore, não daria defeito? Mário não estava. Bobagem, algum amigo faria o conserto. Nem é possível que as três árvores causassem problemas. Uma árvore para si, as outras para os meninos. Mário ausente (FARO, 2001, p. 29).

Como Gertrudes, Aninha preocupa-se em atender a exigência de um pertencimento ao papel tradicionalmente aceito como feminino.
E Mário? Não telefonou nem para as crianças. Novamente pensando. Stop! Sorria, olha o flash! Brilhe agora, boneca. Jogando um beijo para o espelho enorme e calado da parede de seu quarto (FARO, 2001, p. 31).

As palavras da personagem exprimem um sentimento de cobrança sobre si mesma e uma necessidade de manter as aparências. Sendo a ceia natalina uma celebração cristã centrada no conceito de família tradicional, é doloroso para a Aninha não estar ao lado do esposo. De acordo com Scott (1990), os conceitos normativos, expressos nas doutrinas religiosas, educativas, científicas, políticas ou jurídicas, põem em evidência interpretações do sentido dos símbolos e limitam as possibilidades metafóricas.

É nítido, nas protagonistas, a incapacidade de libertação. Isso nos leva a pensar o conceito de gênero de acordo com Butler (2014): gênero é a forma como o masculino e o feminino são construídos e interiorizados. $O$ gênero é, para a autora, uma fabricação, não é nem verdadeiro, nem falso, mas somente produzido como efeitos da verdade de um discurso, assumidos na superfície dos corpos.

Mesmo depois da morte, Gertrudes se encontra ligada ao cônjuge.

Ninguém nunca esclareceu, se a senhora Gertrudes teria morrido na hora exata que descobriram e violentaram seu sagrado segredo, ou se o aguaceiro lhe havia roubado a flor da vida [...]. O fato é que até o último momento, ao fechar o esquife, ainda possuía o frescor dos vivos, a tristeza de quem está partindo e a saudade desmesurada de um ente querido que perdera definitivamente (FARO, 2004, p. 133). 
Aninha também permanece ligada ao marido, e a lembrança causa na protagonista angústia e sofrimento; isso pode ser percebido quando a personagem se encontra sozinha depois da ceia: quando todos vão embora, enche a boca de algodão sintético com o qual enrolara as bolas japonesas e chora alto, "havia tanto algodão, que enxugou o rosto e assou o nariz. Lembra-lhe a neve, muita neve. Aquela viagem à Europa, com Mário" (FARO, 2001, p. 32).

Os perfis femininos retratados em Gertrudes e Aninha refletem uma identidade profundamente marcada pela ideologia do patriarcado, centrada na idealização do masculino e construída no interior de relações de poder e exclusão. Conforme afirma Hall (2011), a ideologia age tanto no nível da formação e das práticas discursivas que compõem o campo social quanto nos níveis rudimentares da identidade e dos impulsos psíquicos. Para o autor, o sujeito é produzido como um efeito do discurso e no discurso, no interior de formações discursivas específicas.

Dessa forma, podemos compreender o comportamento de Gertrudes e Aninha como coloca Lauretis (1994), para quem o gênero, enquanto representação e autorrepresentação, é fruto de diversas tecnologias sociais, de discursos, epistemologias, práticas críticas institucionalizadas e práticas da vida cotidiana, que têm o poder de controlar o campo do significado social e, assim, produzir, promover e implantar representações.

\section{Considerações finais}

Neste artigo, propomos analisar os contos "A ceia de Aninha" e "Gertrudes e seu homem", da escritora Augusta Faro. A análise teve como objetivo refletir sobre a construção das personagens Aninha e Gertrudes. Procuramos observar o lugar ocupado pelas personagens femininas na estrutura ideológica dominante patriarcal, buscando olhar a representação dos papéis de gênero.

Diante do fracasso do relacionamento amoroso, as personagens buscam soluções para seus tormentos. A solução encontrada por Gertrudes é a construção de um marido imaginário, e Aninha, na solidão, busca apagar o vazio deixado pela ausência de Mário, embora as lembranças e a ações da protagonista sejam direcionadas ao marido.

A representação das relações de gênero entre feminino e masculino nos contos em questão e a maneira como Aninha e Gertrudes assumem os seus lugares denunciam a violência simbólica e o sistema de opressão vivido pelas personagens. Aninha e Gertrudes não são capazes de questionar a sua condição, mas buscam caminhos de pertencimento à estrutura patriarcal. Existe em ambas uma impossibilidade de libertação, não há um deslocamento das personagens. A representação do feminino em Aninha e Gertrudes mostra como a desigualdade de gênero é profundamente naturalizada nas ações, nos corpos, nos pensamentos, nas formas simbólicas. 


\section{Aninha, Gertrudes and their sorrows: the female condition in Augusta Faro's writing}

\begin{abstract}
In this article we aim to reflect on the portrayal of the feminine identity in Augusta Faro's short stories "A ceia de Aninha" (2001) and "Gertrudes e seu homem" (2004). We take as theoretical support the dialogue between Cultural Studies, Gender Theories and Literature. The interaction of these fields allows us to reflect on how the literary text recapture and problematizes some cultural practices' aspects, and, conceptualizing identity as a fluid discursive cultural construction, we seek to perceive how the short stories (re) produce universes that legitimize the ways of understanding the masculine and the feminine. We aim to analyze the way in which Aninha and Gertrudes, the short stories' protagonists, deal with the gender roles and attempt to solve the conflicting aspect of their existential condition.
\end{abstract}

Keywords: Culture. Gender. Identity.

\section{Referências}

BAUMAN, Zygmunt. Identidade: entrevista a Benedetto Vecchi. Rio de Janeiro: Jorge Zahar, 2005.

BEAUVOIR, Simone. O segundo sexo. 2. ed. Rio de Janeiro: Nova Fronteira, 2009.

BOURDIEU, Pierre. A dominação masculina. Rio de Janeiro: Bertrand Brasil, 2002.

. A dominação masculina revisitada. Campinas: Papirus, 1998.
Razões práticas: sobre a teoria da ação. Campinas: Papirus, 1996.

BUTLER, Judith. Problemas de Gênero: feminismo e subversão da identidade. Rio de Janeiro: Civilização Brasileira, 2013.

. Regulação do Gênero. Cadernos Pagu, Campinas, v. 42, p. 249-274, jan./jun. 2014.

CANDIDO, Antônio. Literatura e sociedade: estudos de teoria e história literária. São Paulo: T. A. Queiroz, 2000.

DERRIDA, Jacques. A escritura e a diferença. São Paulo: Perspectiva, 1976.

EDGAR, Andrew; SEDGWICK, Peter. Teoria Cultural de A a Z: conceitos-chaves para entender o mundo contemporâneo. São Paulo: Contexto, 2003.

FARO, Augusta. Gertrudes e seu homem. In: RUFFATO, Luiz (Org.). 25 mulheres que estão fazendo a nova literatura brasileira. Rio de Janeiro: Record, 2004. p. 126-133.

. A ceia de Aninha. In: A friagem. São Paulo: Global, 2001. p. 29-32.

HALL, Stuart. A Identidade cultural na pós-modernidade. Rio de Janeiro: DP\&A, 2006.

. Quem precisa da identidade? In: SILVA, Tomaz Tadeu (Org.). Identidade e diferença: a perspectiva dos estudos culturais. Petrópolis: Vozes, 2011. p. 103-133.

Representation cultural representations and signifying pratices. Londres: The Open University, 1997.

HARAWAY, Donna. Manifesto ciborgue: ciência, tecnologia e feminismo-socialista no final do século XX. In: SILVA, Tomaz Tadeu de. Antropologia do Ciborgue - as vertigens do pós-humano. Belo Horizonte: Autêntica, 2000. p. 39-129.

LAURETIS, Teresa de. A tecnologia do Gênero. In: HOLLANDA, Heloísa Buarque de. Tendências e Impasses. O feminismo como crítica da cultura. Rio de Janeiro: Rocco, 1994. p. 207-242. 
MONTERO, Rosa. História de Mulheres. Rio de Janeiro: Agir, 2007.

MOSER, Walter. Estudos literários, estudos culturais: reposicionamentos. Literatura $e$ Sociedade, São Paulo, v. 3, p. 62-76, 1998. Disponível em: <http:/www.revistas.usp.br/ ls/issue/view/17>. Acesso em: 22 nov. 2008.

NICHOLSON, Linda. Interpretando o gênero. Revistas de Estudos Feministas, Florianópolis, v. 8, n. 2, p. 9-41, 2000. Disponível em: <https://periodicos.ufsc.br/index.php/ ref/issue/view/312/showToc $>$. Acesso em: 22 out. 2008.

SCOTT, Joan. Gênero: uma categoria útil de análise histórica. Educação e Realidade, Porto Alegre, v. 16, n. 2, p. 5-19, 1990.

História das mulheres. In. BURKER, Peter. A escrita da história: novas perspectivas. São Paulo: Unesp, 1992. p. 62-95.

. Igualdade versus diferença: os usos da teoria pós-estruturalista. Debate feminista. São Paulo: Melhoramentos, 1999.

SILVA, Tomaz Tadeu. A produção social da identidade e da diferença. In: SILVA, Tomaz Tadeu (Org.). Identidade e diferença: a perspectiva dos estudos culturais. Petrópolis: Vozes, 2011. p. 73-102.

WOODWARD, Kathryn. Identidade e diferença: uma introdução teórica e conceitual. In: SILVA, Tomaz Tadeu (Org.). Identidade e diferença: a perspectiva dos estudos culturais. Petrópolis: Vozes, 2011. p. 7-72. 